\title{
A ÉTICA EM STEVEN UNIVERSE: \\ UM MODO DE TRANSVERSALIZAR A IDENTIDADE ATRAVÉS DO HERÓI
}

Samuel Possidonio de Soura*

Rosemary Lapa de Oliveira**

\begin{abstract}
RESUMO: Este artigo discute a possibilidade de uma narrativa de ficção proporcionar o desenvolvimento de conhecimentos em valores humanos, através da narrativa do herói. Diante disso, o objetivo principal perseguido foi discutir a viabilidade da mediação do texto de animação, através de seu herói (personagem principal) na construção de valores em sala de aula. Tomamos como mote de discussão a animação Steven Universe, a qual oferece mediação de significados concernentes a temas que transversalizam a aprendizagem, principalmente tratando-se de ideologias de minorias. Para as discussões aqui levantadas, apresentamos um estudo do documento filmico, através do recorte de um episódio, privilegiando a abordagem sobre ética, cidadania e justiça, considerando as orientações governamentais através dos Parâmetros Curriculares Nacionais. Para tanto, foram considerados textos sobre educação amparados em Freire (1980) e discussões sobre identidade e identificação, principalmente com Bettelheim e Lacan. Na sala de aula, a discussão ética é possível dentro da reflexão: "e se fosse eu no lugar do herói, o que faria"? Essa é uma dinâmica que esses autores indicam - incluindo o episódio do próprio Steven discutido aqui - para que haja a reflexão ética e estética da obra dentro da escola, viabilizada por um desenho animado, de forma criativa e lúdica.
\end{abstract}

Palavras chave: identidade, identificação, desenho animado, formação de professores

ETHICS IN STEVEN UNIVERSE:

A WAY TO TRANSVERSALIZE IDENTITY THROUGH THE HERO

\begin{abstract}
This article discusses the possibility of a fictional narrative providing the development of knowledge in human values. Therefore, the main objective pursued was to discuss the viability of the mediation of the animation text, through its hero (main character) in the construction of values in the classroom. We take the Steven Universe animation as a motto for discussion, which offers mediation of meanings concerning issues that cross-section learning, especially in the case of minority ideologies. For the discussions raised here, we present a study of the film document, through the clipping of an episode, privileging the approach on ethics, citizenship and justice, considering the government guidelines through the National Curriculum Parameters. To this end, texts on education supported by Freire (1980) and discussions on identity and identification were considered, mainly with Bettelheim and Lacan. Within the classroom, ethical discussion is possible within the reflection: "and if it were me in the place of the hero, what would I do"? This is a dynamic that these authors indicate - including Steven's own episode discussed here - in order that there can be an ethical and aesthetic reflection of the work within the school, made possible by a cartoon, in a creative way.
\end{abstract}

Keywords: identity, identification, cartoon, teacher education

\footnotetext{
* Psicólogo bacharel e licenciado. Estudande de especialização em Neuropsicologia na UNIFTC. Mestrando do Programa de Pós-Graduação em Educação e Contemporaneidade PPGEDUC/UNEB.

Email: samuel.possi@gmail.com ORCID: https://orcid.org/0000-0003-1169-9470

** Doutora em educação. Professora titular da Universidade do Estado da Bahia (UNEB).

E-mail: rloliveira@gmail.com ORCID: https://orcid.org/0000-0003-1165-8265
}

\begin{tabular}{|l|l|l|l|l|l|l|}
\hline APRENDER - Cad. de Filosofia e Psic. da Educação & Vitória da Conquista & Ano XIV & n. 24 165-178 & Jul./dez. 2020 \\
\hline
\end{tabular}




\section{STEVEN UNIVERSE ENTRA EM CENA}

Nos últimos anos, os conteúdos midiáticos, a indústria do consumo e do entretenimento popularizaram-se nos setores da sociedade, e o acesso cada vez maior à rede de internet se ampliou muito. Com isso, vários efeitos na educação têm sido vistos, inclusive o uso de dispositivos móveis, através de programas, aplicativos e conteúdos disponibilizados na internet como ferramentas para mediar o aprendizado, buscando em conteúdos midiáticos, tais como filmes, animes, revistas em quadrinhos, desenhos animados, antes estigmatizados, caminhos para a aprendizagem, o que podemos perceber até nas escolhas de textos para os livros didáticos.

Para analisarmos como a educação pode se inovar e assim acompanhar em seu tempo novas narrativas e ferramentas, devemos relembrar a ideia de que a aprendizagem não é privativa do espaço escolar. Vygotsky (2001) sustenta o pensamento de que o saber só se torna tal quando é atravessado pela experiência pessoal, o autor defende o aprendizado em uma perspectiva histórico-cultural. A discussão sobre o lugar no qual se dá a aprendizagem nos amplia os horizontes do muro da escola e nos oferece a cultura como uma ferramenta de mediação de aprendizados.

É nesse emaranhado de ideias e posturas emergentes que propomos o desenho animado como dispositivo de aprendizagem, através da construção de narrativas lúdicas da jornada do herói/heroína que proporcionam experiências psíquicas de entendimento de si, do outro, do mundo, conforme defende Bettelheim (2002). Mesmo que haja uma produção capitalista sustentando a indústria do entretenimento, uma animação é capaz de oferecer elementos para a construção de significados e discursos através de sua narrativa, inclusive alcançando idades que não cabem apenas no rol da infância, atingindo jovens e adultos, a depender das temáticas envolvidas.

Pela via do desenho, a criança solta sua imaginação e procura criar significados e sentidos para as coisas do mundo, mesmo que esses significados sejam permeados pelos ideais dos produtores de determinada animação (MIRANDA, 1978), afinal, a linguagem imagética é muito mais acessível por sua natureza polissêmica que a linguagem verbal, notadamente a escrita, proporcionando, com sua ludicidade, aprendizagens de comportamentos, sensações, emoções e outros tantos conhecimentos. Em suas narrativas, são apresentadas as peripécias de um herói sempre frágil que consegue superar suas dificuldades, o que auxilia a criança a lidar com as aprendizagens por que passa para se tornar adulta, conforme argumentado por Bettelheim (2002).

O que ocorre é uma série de situações socioculturais que encaminham os espectadores/fãs para uma produção de significados frente ao discurso apresentado. Esse fenômeno, uma vez trazido para a sala de aula, pode mediar aprendizagens, através de uma nova realidade que aponta para a diminuição das narrativas orais/escritas e aumento de narrativas audiovisuais na contemporaneidade, ou, como alguns autores definem, na pós-modernidade. 
Dentro dessa perspectiva, podemos observar os sujeitos que se identificam com as identidades geek/nerd/otaku se beneficiam das produções midiáticas, que são narrativas de super-heróis, em adaptação cinematográfica - ou para a televisão - de histórias em quadrinhos ou Mangás (que são histórias em quadrinhos japonesas), animações seriadas ou em filmes, animes (que são animações no estilo japonês), dentre outros. Tais produções afetam a forma com que esses sujeitos veem o mundo e percebem a si, pois essas narrativas os atravessam (BICCA et al, 2013; GUSHIKEN e HIRATA, 2014). Mas o que essas animações podem de fato proporcionar e como elas podem ser utilizadas na educação provoca grandes dúvidas em educadores e educadoras que não possuem prática ou envolvimento com esse tipo de linguagem.

Este artigo possui como questão norteadora: como uma narrativa de ficção pode proporcionar o desenvolvimento ou construção de conhecimentos em valores humanos? Diante disso, o objetivo principal perseguido é discutir a viabilidade da mediação do texto fílmico de animação, através de seu herói (personagem principal) na construção de valores em sala de aula.

Tomamos como mote de discussão a animação Steven Universe (SU), narrativa considerada um dos produtos televisivos de maior sucesso em várias faixas etárias, incluindo adultos, considerando os valores humanos e as características humanas que enseja, tais como liderança, maternidade, relações sociais e amorosas, representatividade, fraternidade, preconceito, identidade de gênero, homoafetividade e outros temas. Vale lembrar de toda a tentativa da Educação em abordar temas emergentes no ambiente escolar que desenvolvam significados junto às crianças e adolescentes, e que ofereçam suporte psicológico para o sujeito em formação. Steven Universe oferece essa mediação de significados concernentes a esses temas, que transversalizam a aprendizagem, principalmente tratando-se de ideologias de minorias. É importante se compreender a forma com que o programa faz essa mediação de significados, auxiliando à criança e ao adolescente na construção de sua personalidade a partir da narrativa, em meio às adversidades da vida em sociedade.

Para a discussão aqui levantada, optamos por fazer um estudo do documento fílmico, através do recorte de um episódio, privilegiando a abordagem sobre ética, cidadania e justiça, considerando as orientações governamentais através dos Parâmetros Curriculares Nacionais (PCNs). A relevância em se discutir os Parâmetros Curriculares Nacionais se pauta em como a educação vem sendo pensada ao longo dos anos no Brasil. Através desses documentos, instituiu-se formas e possibilidades de se discutir questões socioculturais e subjetivas nos currículos. A indagação que pode ser formulada é justamente a inserção da subjetividade na educação, sua implicação para o contexto e a sua importância para os sujeitos em seus percursos de construção e reconstrução da subjetividade. Ora, por que então se discutir subjetividade na sala de aula? O que é subjetividade? O que preconizam os Parâmetros Curriculares Nacionais? São perguntas reflexivas possíveis de se desenvolver ao se pesquisar esses elementos.

É importante discutir as bases desses pensamentos, apontados pelos PCNs através dos eixos da educação para a UNESCO: Aprender a conhecer; aprender a fazer; aprender a viver; e aprender a ser 
(BRASIL, 2000). Em consoante com essa postura, pode-se articular a ideia que Morin postulou (2000), de que o ensino deveria ser atravessado pela condição humana, e no caso particular deste texto, tendo a linguagem fílmica e o desenho como vias de produção e simbolização da vida humana, considerando essas produções artístico-culturais como possíveis ferramentas para se trabalhar e abordar a condição humana, inclusive em diversos contextos.

Os títulos das seções se apresentam como se fossem títulos de episódios, aproximando as discussões do mote em foco. Adiante explicitamos o percurso metodológico, depois apresentamos reflexões contidas nos PCNs, em seguida apresentamos o herói privilegiado para estudo neste texto, na intercessão com a educação e a psicanálise. Logo após, apresentamos a análise de um episódio da série Steven Universe e chegamos às considerações finais.

\section{ELEMENTOS DE AÇÃO}

Esta pesquisa qualitativa tem como método a análise documental, que constitui-se através de análise de materiais que irão compor a pesquisa, no caso um dos episódios do seriado de animação Steven Universe e o texto dos PCN. O documento em questão é uma fonte primária e o principal instrumento de coleta de dados, que se dá a partir da sua leitura e análise de informações para a sistematização e destaque dos pontos propostos para a discussão da pesquisa (SÁ-SILVA, et al, 2009). Mesmo sabendo da ocorrência de documentos mais recentes, o PCN será privilegiado por conta das discussões mais direcionadas sobre ética que traz.

A análise documental foi construída em duas etapas: a etapa 1 foi estipulada de forma a compreender os Parâmetros Curriculares Nacionais (PCNs) e os documentos desse bloco são os PCNs da $1^{a}$ à $4^{a}$ série, terceiro e quartos ciclos do Ensino Fundamental e os PCNs do Ensino Médio. A etapa 2 compreende descrição e análise da série animada Steven Universe e um de seus episódios. Essas etapas foram separadas apenas para fins de organizar melhor a pesquisa e a composição deste artigo.

Como dispositivo de pesquisa, foi utilizada a Análise de Conteúdo de Bardin (2011), que estabelece retirada de trechos do conteúdo do material, separando-os em categorias, elencadas pelos objetivos e frequência dos principais temas observados no estudo. Segundo o autor, a análise temática segue um esquema que é a pré-análise, a exploração do material, tratamento dos resultados obtidos e a interpretação.

Foram analisados materiais e levantadas categorias de análise da seguinte forma: os PCNs foram tratados enquanto documento governamental que orienta o processo de ensino e aprendizagem no território nacional. Compreendemos que há campo de discussão sobre tal documento, tanto no âmbito de sua produção, quanto no campo epistemológico, no entanto, não nos ateremos a essas discussões, fartamente publicadas em diversos textos acadêmicos. Interessa-nos, aqui, levantar, dentre as categorias descritas nesse documento como transversais ao ensino, aquela que se aproxima da discussão sobre 
identidade, a qual identificamos como ética. A partir desse eixo temático transversal, foram selecionados episódios específicos da série animada, para que assim conseguíssemos comparar a viabilidade temática de Steven Universe com temas transversais de documentos da educação.

Segundo os PCNs dos anos iniciais (BRASIL, 1997), os temas transversais, incorporados ao currículo, compõem um conjunto articulado e aberto a novos temas, buscando um tratamento didático que contemple sua complexidade e sua dinâmica, dando-lhes a mesma importância das áreas convencionais. Ainda conforme o citado documento, o currículo ganha em flexibilidade e abertura, uma vez que os temas podem ser priorizados e contextualizados de acordo com as diferentes realidades locais e regionais e outros temas podem ser incluídos. O conjunto de temas transversais explicitados pelo documento é: “[...] Ética, Meio Ambiente, Pluralidade Cultural, Saúde e Orientação Sexual [...]” (p. 21) e indicam uma metodologia de inclusão dessas discussões no currículo, através de tratamento didático. Dentro da ética, encontramos subtemas como: consciência social, política e de si próprio [?], do corpo, autoconhecimento, autoconfiança, autonomia, construção de identidade, capacidade física, afetiva e de relação interpessoal. Esses valores serão mote de análise e proposição didática, considerando um dos episódios de Steven Universe.

A categoria elencada para a análise foi Ética, cidadania e justiça, que por sua vez, aborda temas como “[...] deveres e direitos, atitudes, solidariedade, respeito e justiça, cooperação, contra discriminações de qualquer tipo [...]", abordadas nos temas dos PCNs (BRASIL, 1997, p. 9)

Dentro dessa categoria, foi necessário compreender a viabilidade da pesquisa para que fosse possível desenvolver este artigo. Então, como critérios de inclusão, foram listados: episódios que possuem relação direta com a categoria temática elencada (vide explicação da análise de conteúdo de Bardin) a partir dos PCNs, definidas acima; episódios em que o tema geral que tenha relação com a categoria dos PCNs atravesse todo o episódio, ou seja, foram descartados episódios em que o tema aparecia em segundo plano ou episódios que possuem uma variação alta de temas apresentados; e depois, foi realizada escolha de um dos episódios que deixasse mais nítida essa relação. Isso implica na escolha do seguinte episódio: Amigo monstro (episódio 23 da primeira temporada, exibido em 2014, segundo site Wikipédia (2019))

A escolha desse episódio se dá também porque ele levanta discussões sobre empatia, respeito, compreensão, igualdade e atitude contra a discriminação como posturas necessárias, o que coaduna com a proposta de análise dentro da tríade ética, cidadania e justiça. A partir daí, foi realizado um resumo, abordando os principais pontos temáticos e discussões do referido episódio.

Por fim, por conta de dados escassos sobre Steven Universe dentro do mundo acadêmico, este artigo buscou dados em sites geridos pelos próprios fãs, a partir de uma perspectiva etnográfica, que é a inclinação à construção de saber a partir de sujeitos de uma cultura. Vale lembrar que Steven é parte de narrativas de ficção que os sujeitos que se identificam como geeks, nerds e otakus (explicados na introdução) consomem, e isso justifica a utilização de sites como Fandom e Wikipédia de Steven Universe 


\section{NOTÍCIAS DOS PARÂMETROS BRASILEIROS}

Segundo exposto no site oficial do Ministério da Educação do Brasil (2018), os Parâmetros Curriculares Nacionais “[...] Foram feitos para auxiliar as equipes escolares na execução de seus trabalhos. Servirão de estímulo e apoio à reflexão sobre a prática diária, ao planejamento de aulas e sobretudo ao desenvolvimento do currículo da escola, contribuindo ainda para a atualização profissional".

Tal intenção assim explicitada gera uma concepção de educação, pois ali percebemos o tratamento dos conhecimentos por áreas, além de valorizar temas e políticas a serem trabalhados na escola dentro dos PCN, sem adição de disciplinas, isso é, tratam de assuntos e temas que devem ser desenvolvidos de forma transversal (BRASIL, 2000). É importante, igualmente, ressaltar que há vários documentos, abarcando os vários segmentos da educação, detalhando ações pedagógicas curriculantes. Neste texto, privilegiamos aqueles concernentes às séries iniciais no ensino fundamental, às séries finais e ao ensino médio.

Os PCNs do quarto e quinto ciclo apontam alguns aspectos importantes que compreendem assuntos sobre a cidadania, atitude e valores, como por exemplo:

[...] a compreensão da cidadania como participação sócio-política e o exercício de direitos e deveres políticos [...] solidariedade [...] respeito [...] postura crítica $[\ldots]$ assistencialismo $[. .$.$] recusa de injustiças [...] respeito [...] valorização da pluralidade$ cultural nacional e de outros povos [...] atitude contra discriminação de qualquer ordem [...] desenvolvimento do autoconhecimento, autoconfiança e das capacidades afetivas, físicas, cognitivas e de relação interpessoal [...]atitude responsável sobre a saúde pessoal e coletiva... [...](BRASIL, 1998, p. 6) Destacam-se daí utilização de temas que versem sobre a compreensão da vida em sociedade, a consciência política, atitudes e valores de convivência social, desenvolvimento da autoconfiança, do autocuidado, do corpo e de questões socioculturais e de saúde. Além de apontar expressões por diversas vias de comunicação.

Os PCNs do ensino fundamental priorizam a formação humana e de construção da subjetividade e das relações sociais, sem a necessidade de se criar componentes curriculares além dos comuns, isso é: há o que é chamado Temas Transversais São alguns dos temas transversais: ética, saúde, orientação sexual, meio ambiente, trabalho e consumo, pluralidade cultural. Em adição, o documento ainda aponta pontos de trabalhos comuns da comunidade escolar: autonomia, interação e cooperação, atenção à diversidade, disponibilidade para a aprendizagem. E acrescenta ainda questões da juventude e da adolescência, como construção de identidade, a condição da vida juvenil, trabalho, família, cultura e vida pública (BRASIL, 1998, p. 8)Entendendo essas discussões como importantes no campo do desenvolvimento psicossocial do indivíduo e considerando, como Freire (1980, p. 25), que “[...] os homens são capazes de agir conscientemente sobre a realidade objetivada", optamos por apontar a possibilidade didática de levantamento de discussões sobre identidade, dentro do amplo tema transversal 'ética', através de um 
desenho animado (Steven Universe, ou SU) que, por estar disponível em rede de televisão aberta, fechada e no YouTube, deve ser de conhecimento prático de crianças e jovens, estudantes da educação básica.

Ainda segundo Freire (1980), a práxis humana é a unidade indissolúvel entre ação e reflexão sobre o mundo, o que resulta em conhecimentos, num processo natural em que o sujeito vai se humanizando e, de forma autônoma, vai fazendo escolhas. Considerando a prática comum de crianças e jovens se interessarem por desenhos animados, apresentamos a proposta que segue.

Vale apontar que o Brasil entrou em um processo de mudança no currículo através da Base Nacional Comum Curricular (BNCC) que orientam e norteiam os currículos dos sistemas e redes de ensino de todo o país, mas não substituindo os PCNs. O documento aborda em sua introdução a orientação através dos princípios éticos, políticos, e estéticos para uma formação humana e o desenvolvimento de uma sociedade justa. Para isso, o documento cita a Lei de Diretrizes e Bases da Educação e as Diretrizes Curriculares Nacionais da Educação Básica (DNC) como dispositivos de orientação e fundamentação da BNCC.

A nova Base aponta, o que o documento chama de competências gerais, indicando que contribuem para os direitos em educação e para a pedagogia. Esse conceito para o documento é definido como: “é definida como a mobilização de conhecimentos (conceitos e procedimentos), habilidades (práticas, cognitivas e socioemocionais), atitudes e valores para resolver demandas complexas da vida cotidiana, do pleno exercício da cidadania e do mundo do trabalho" (BRASIL, 2019, p. 8).

ABNCC aponta a necessidade da educação fomentar mudanças na sociedade, e que as propostas estão alinhadas com a Agenda 2030 da Organização das Nações Unidas.

O documento aponta dez competências básicas, dentre as tais é possível tecer relações com os temas transversais com os PCNs - ao menos as competências básicas. Esse artigo se propôs a abordar os PCNs, tendo em vista essa proposta, não discutimos aqui toda a relação das competências básicas com alguns temas transversais.

\section{STEVEN E UMA FRAÇÃO DE SEU UNIVERSE}

Steven Universe (SU), como citado anteriormente, é uma animação criada e produzida por Rebecca Sugar, uma animadora, compositora e diretora norte-americana. Seu episódio piloto foi lançado em julho de 2013 e o seu lançamento oficial se deu em 04 de novembro de 2013 (WIKIPEDIA, 2019). Como é um desenho animado contemporâneo não há dados acadêmicos ou bibliografia suficiente para apresentar os episódios da série, o que justifica as fontes utilizadas para a composição dessa seção, além de conhecimento empírico sobre a obra.

SU possui cinco temporadas e teve sua estreia em 2013 nos Estados Unidos, e 2014 no Brasil. Possui ainda um filme (Steven Universe: The Movie; Dir; Rebecca Sugar), lançado em 2019 nos Estados Unidos da América (EUA), no mesmo canal que exibe sua série. No Brasil, foi exibido pela Cartoon 
Network Brasil, um mês após a estreia nos EUA. Além dessas produções, a animação conta ainda com uma temporada de epílogo, chamada Steven Universe Future (Steven Universe Futuro, no Brasil), contando o fechamento dos acontecimentos da história de Steven (WIKIPEDIA, 2019). Atualmente, é possível ter acesso aos episódios de Steven Universe através de serviços de streaming da companhia Netflix e da Amazon Prime; além do acesso pelo canal da Cartoon Network em assinaturas de TV. Além desses acessos pagos, é possível encontrar o filme e alguns episódios no YouTube de forma gratuita, ampliando, assim, o acesso.

A criadora imaginou um desenho que juntasse realidade e fantasia, utilizando também a inspiração de seu irmão caçula Steven Sugar, exprimindo o personagem principal. Sugar busca incentivar as crianças de hoje a serem elas mesmas, sem a ideia imperativa de se ajustar em uma sociedade, por conta disso, a série aborda temas inclusivos, com um impacto de (em média) 2 milhões de telespectadores (nos EUA e no mundo) por episódio, em 2013 (FANDOM, 2019).

A seguir, desenvolvemos o resumo do episódio escolhido para a análise e discussões. A escrita do resumo se deu a partir da leitura fílmica feita do episódio pelos próprios pesquisadores. Nesse desenho animado, a personagem principal é um garoto de aproximadamente dez anos que tem poderes especiais por ser filho de uma extraterrestre - que morre para lhe dar a vida - e um humano. Nosso herói é criado por seres extraterrestres da raça de sua mãe que lhe ensinam como lidar com os seus poderes. Steven é um garoto comum, sem muitos atrativos físicos ou intelectuais, um herói com quem qualquer um pode se identificar. A sua única diferença é um poder herdado de sua mãe, com o qual ele está aprendendo a lidar.

Essas características do herói do anime aproxima crianças e jovens desse personagem, pois suas práticas, conforme preconizado por Freire (1980), são ações conscientes sobre a realidade objetivada, a qual vai construindo uma identidade pessoal, social, familiar, ecológica, enquanto unidade indissolúvel entre ação e reflexão sobre o mundo.

\section{AMIGO MONSTRO}

O episódio Amigo Monstro (STEVEN UNIVERSO, 2014) começa com as Crystal Gems ${ }^{1}$ batalhando contra um monstro gelado dentro de uma caverna de gelo. Enquanto as três estão lutando, Steven se mantém mais afastado assistindo à luta. Nesse período da história, o rapazinho não desenvolveu seu poder completamente, então ele não ajuda nas missões. Um fato curioso é que quando um braço do monstro de gelo cai, Steven segura no seu e comenta que deve ter doído, demonstrando empatia; até que o monstro é derrotado e as Gems podem, assim, seguir com a missão de capturar uma gem estrela

\footnotetext{
${ }^{1}$ São um grupo dissidente, originalmente eram apenas Gems, uma raça alienígena de jóias preciosas que podem projetar seus corpos (de luz tangível) para fora das gemas enquanto essa permanece presa ao corpo. São Crystal Gems Garnet, Ametista e Pérola. (FANDOM, 2019).
} 
cadente. Ao derrotar o monstro, a caverna começa a desmoronar e para salvar Steven, Garnet embolhao com seu poder, isto é, com magia, o envolve com uma bolha, como se ele estivesse dentro de uma bolha de sabão da cor vermelha, e o manda para o templo onde Steven vive com as Crystal Gems [qual?] através de sua magia.

No templo, Steven aparece embolhado e contempla outras pedras preciosas, outras gems enlouquecidas, embolhadas, apenas em forma de gems ${ }^{2}$ Ele então tenta sair da bolha, estourando-a, entretanto cai sobre outra bolha, fazendo com que ela libere uma gem que começa a se formar.

As gems são seres de luz, seu corpo é luz tangível, mas suas pedras é que são de verdade "gem". Quando uma gem é ferida de forma fatal, ela dissipa a sua forma física e volta ao seu estágio de pedra. A pedra que Steven derruba é de uma gem corrompida - esse nome é dado para as gems que sobreviveram à grande batalha gem, mas tiveram danos na mente, isso fez com que elas virassem monstros. Uma gem então começa a sair da sua forma de pedra e construir sua forma de luz tangível, mas Steven reconhece: é a Centípoda, um monstro que eles lutaram em episódios anteriores e capturaram. (Ibidem)

A Centípoda tem forma de centopéia, mas aparenta ter um tamanho de um cachorro, possui aproximadamente [?] seis patas, e sua cabeça lembra uma planta carnívora, com olho dentro da boca e uma cabeleira branca ao redor de sua cabeça. (STEVEN UNIVERSE, 2014)

As outras Crystal Gems aparecem e tentam atacar a Centípoda reformada, mas Steven protege a gem corrompida, com o discurso de que ele iria protegê-la, treiná-la e ajudá-la. Garnet o permite e, assim, o episódio se passa com Steven acompanhando a Centípoda, mostrando a praia, dando-lhe batatas fritas para comer. Na praia, a Centípoda ataca uma gaivota que havia atacado Steven, cuspindo ácido pela boca, o que deixa Steven feliz com o progressoe ansioso para contar às Gems, pois as corrompidas Não raciocinam, e nem defendem - mas Centípoda está fazendo os dois, o que seria muito para uma gem corrompida.

Steven vai à casa na praia, onde mora com as Crystal Gems e mostra que treinou o monstro. Ele faz o som da gaivota "squatch", e o monstrinho cospe ácido pela casa toda vez que ele reproduz o som. As Crystal Gems desaprovam a relação, mas a conversa acaba com o consenso de levar a Centípoda para as cavernas geladas, pois ela possui ácido e pode ajudar na missão de achar a Estrela Cadente. E assim, todos voltam para a missão com a Centípoda abrindo buracos nas paredes de neve e gelo até a sala em que a Estrela Cadente se encontra. (Ibidem)

Nesse momento, Garnet põe suas luvas para não se machucar, mas a Centípoda se assusta, pois já havia levado golpes da Garnet com aquelas luvas de batalha e começa a cuspir ácido por todos os lados. As Crystal Gems começam a se preparar para batalhar contra o monstro e Steven se desespera, "não

\footnotetext{
${ }^{2}$ As Crystal Gems estão no planeta Terra há milhares de anos, elas protegem os seres viventes desde a rebelião com seu planeta natal. Essa revolta gerou uma série de Gems corrompidas, isso é, suas mentes enlouqueceram, elas ficaram com o corpo modificado, de monstro, e algumas ameaçam a vida na Terra, logo, essas dissidentes lutam contra os monstros, desfazem a forma física e embolham, para que não faça mal a si e nem à vida no planeta. Daí são recolhidas no templo.
} 
ataquem ela, está apenas assustada”, falava Steven enquanto as Crystal Gems desferem golpes contra a Centípoda. (Ibidem)

Em um dado momento, Steven consegue conter a Centípoda com um abraço, fazendo com que as Crystal Gems não conseguissem desferir outro golpe no pequeno monstro do tamanho de um cachorro. Steven então pede desesperadamente para a Centípoda se acalmar, enquanto ela derrama ácido nas costas do menino, que continua tentando fazê-la lembrar da praia, de como ela o protegeu; da batata frita... Até que uma estalactite cai do teto e a Centípoda empurra Steven para salvá-lo... A estalaquitite cai sobre a monstrinha, ferindo-a fatalmente e, assim, dissipando a sua forma de luz tangível, e recolhendoa na sua forma de pedra. (Ibidem)

Seu olho, que é a sua pedra, rola em direção de Steven, que a pega de forma cuidadosa e com muita tristeza nos olhos, diz: “ela só estava me protegendo". Nesse momento, o protagonista faz algumas perguntas às Crystal Gems, do porquê da Centípoda estar assim, se as gems corrompidas vão poder voltar a ser como eram antes. Pérola [quem é Pérola?] e Garnet falam sobre os poderes curativos da mãe do Steven, a Rose Quartz, e como Steven tem sua pedra no umbigo, talvez Steven consiga ajudar as Gems corrompidas quando ele desenvolver os seus poderes. Mas era difícil para Rose, ela não conseguiu salvar as corrompidas (STEVEN UNIVERSE, 2014).

Steven embolha a gem corrompida com suas mãosfazendo as Crystal Gems se admirarem, pois ele nunca havia embolhado antes -, e o rapaz então pede à Centípoda que esperasse por ele e a promete que a salvará da corrupção, Centípoda (Ibidem).

Nesse episódio, há então um conjunto de valores que são discutidos, e que podem dialogar com temas apontados nos PCNS, como ética, cidadania, justiça, deveres, direitos, atitudes, solidariedade, respeito e justiça, cooperação, atitude contra discriminação de qualquer tipo (BRASIL, 2000), todos esses que redundam em construção psicossocial. Nesse episódio, vemos Steven com empatia até para com seus inimigos: com essa empatia ele demonstra uma ideia de valor que não discrimina o outro, mesmo sendo seu inimigo. Essa própria empatia do Steven aparece ao longo do episódio, em especial com a Centípoda: ele a protege quando as Crystal Gems se põem a atacá-la, se mantém solidário a ela, se propõe a tomar conta dela e cria uma relação de respeito e cooperação com a Centípoda quando retorna à caverna atrás da Estrela Cadente. Essa atitude do personagem principal é estabelecida com base na empatia, a capacidade de sentir o que o outro sente, e esse é o valor que o personagem mais demonstra por toda a série, um importante traço de caráter que pode ser desenvolvido através de mediação. Ao identificar-se com o Steven, a criança que dialoga com a animação pode ser levada a discutir seus comportamentos, refletindo sobre a empatia e, assim, construir a sua identidade cidadã, ética e o respeito às diferenças, temas transversais importantes de serem abordados desde as séries iniciais, conforme indicado também nos PCNS.

Segundo o PCN, das séries iniciais (da primeira série à quarta série), ética também se relaciona às reflexões que podem ser desenvolvidas a respeito das atitudes humanas. O documento aponta de forma 
prática como compreender a questão ética: “A pergunta ética por excelência é: 'Como agir perante os outros?"' (BRASIL, 1997, p. 26). Esse questionamento é extenso e complexo, entretanto o documento indica que a preocupação que se deve ter destaque aqui são os valores de igualdade e equidade ao sujeito se confrontarcom questões dessa natureza. O próprio documento indica o princípio da igualdade como “[...] a necessidade de garantir a todos a mesma dignidade e possibilidade de exercício de cidadania [...]" (ibidem, p. 20).

O episódio de Steven em questão aborda de forma metafórica essa reflexão - o próprio título destaca isso, “Amigo monstro", e é de fato uma concessão de igualdade que Steven projeta no monstro, construindo, assim, o conceito de respeito às diferenças. Esse respeito também é possível de se compreender por conta da empatia que Steven demonstra para a Centípoda, da atribuição de sentimentos a ela e pela sua oposição às Crystal Gems, quando as mesmas queriam ferir a Centípoda. São cenas em que discussões sobre a ética podem ser levantadas dentro de uma sala de aula, mediando o questionamento sobre o que cada estudante faria na posição do Steven, promovendo um exercício reflexivo sobre qual atitude assumir perante o outro, se essa atitude precede de valores de igualdade, dando a mesma dignidade ao outro.

$\mathrm{Na}$ escola, o tema deve aparecer na sala de aula, dentro das disciplinas e do currículo, como prescrevem os PCNs das séries iniciais, no documento é apontado como um tema de extrema necessidade.. À escola, nesse âmbito, cabe realizar um trabalho que viabilize o desenvolvimento dessa atitude de reflexão ética em prol da formação humana; por conta disso, o documento apresenta alguns blocos temáticos, como respeito mútuo, justiça, diálogo e solidariedade, que são princípios da dignidade do ser humano (BRASIL, 1997, [se possível indicar o número da página]).

Uma narrativa como essas é deveras importante para a construção da própria subjetividade. Bettelheim (2002) indica que o herói cerceia um corpo que consegue realizar façanhas incríveis. Um sujeito identificado com um herói pode mediar a realidade através da fantasia, isto é, pode fantasiar produzindo os mesmos feitos, além de ficar mais em paz consigo e seu corpo do jeito que ele é na realidade.

Como dito em Lacan (2003,) a identificação ocorre do sujeito ao significante, e a palavra "Steven Universe" compreende toda a construção indentitária fictícia desse personagem e de seus feitos; uma identificação com Steven traria à tona tudo o que o sujeito especificamente associa com o herói, bem como os sentidos que esse sujeito dá a essas palavras. O personagem é, segundo a própria criadora Rebecca Sugar (2015, referência incompleta), um garoto amigável, carinhoso, solidário, otimista, confiante em si mesmo, empático, criativo, inteligente, alegre, divertido, não guarda mágoas ou ressentimentos, não discrimina nem inimigos, sensível e esforçado em aprender a ajudar a equipe com seus poderes, que se desenvolvem a partir de seu estado emocional e de seu crescimento dentro do show.

Nas missões, o personagem tenta lidar com o maior desafio, se põe prestativo, sempre querendo resolver os problemas de todos, agitado, ansioso e por vezes faz a situação piorar antes de ser resolvida. 
Ainda arrisca sua própria vida por aqueles que precisam de proteção, por aqueles que ele ama, e sempre tenta resolver situações através do diálogo e não da violência, além de acreditar em todos, pois todos precisam de uma chance de serem melhores, o que o faz apoiar a todos e tentar ajudar quem está em sofrimento.

Podemos perceber que a própria construção da identidade de Steven já contém elementos éticos envolvidos. Dentro da educação, compreendendo que nos processos sócioculturais os sujeitos se identificam entre si e com valores, é possível esperar uma certa identificação aos elementos que Steven apresenta. Seguindo a ideia da psicanálise apontada acima, de que a identificação é com o significante, então se identificar com Steven pressupõe uma possibilidade discursiva dos significantes que envolvem a identidade desse herói e como os sujeitos o enxergam, como os sujeitos o idealizam e se colocam a ser igual a esse outro fictício, permitindo o sujeito a construir defesas para o mundo e/ou apaziguar anseios da realidade, como aponta Bettelheim (2002, p. 5).

\section{FECHANDO O EPISÓDIO}

Este artigo teve como principal objetivo discutir a viabilidade da mediação do texto fílmico de animação, através de seu herói (personagem principal) na construção de valores em sala de aula. Nessa perspectiva, a utilização de elementos culturais pode viabilizar discussão e desenvolvimento de atitudes dentro da sala de aula. Narrativas de ficção, como desenhos animados, são parte desses elementos culturais, e a animação em questão é um grande laboratório de desenvolvimento dessas atitudes e valores, que estão de acordo com os blocos temáticos prescritos nos PCNs: Steven vê a Centípoda como igual, atribui-lhe valor de igualdade, e a respeita; o personagem se coloca de forma justa e solidária para compreender e defender sua amiga monstro. Apenas um episódio do desenho animado em questão nos mostra a viabilidade de utilizarmos essas produções em contextos escolares, por estarem de acordo com o que prescrevem documentos oficiais da educação básica. Isso porque, por meio da metáfora, é possível discutir transversalmente temas orientados através de documentos oficiais da educação básica. Os desenhos animados, histórias em quadrinhos, mangás, animes etc possuem um estigma social de ser algo meramente de entretenimento, ou "de criança", entretanto essas histórias são importantes na criação de identidade do sujeito, que ocorre através da identificação com o outro, através de suas práxis.

A identificação, comentada aqui, é com os aparelhos discursivos e as associações que o sujeito consegue tecer a partir de suas vivências. A narrativa oferece uma série de conteúdos e de discursos, como visto em Steven Universe. A construção do personagem e suas atitudes demonstram um herói empático, que dialoga e que protege o outro, mesmo sendo inimigo, demonstrando respeito.

Dentro da sala de aula, a discussão ética é possível porque o sujeito irá se identificar ou não com o herói, e fará assim a reflexão indicada "e se fosse eu no lugar do herói, o que faria"? Essa é uma dinâmica que esses autores do presente artigo indicam - incluindo o episódio do próprio Steven discutido aqui - 
para que haja a reflexão ética e estética da obra dentro da escola, viabilizada por um desenho animado, de forma criativa e lúdica.

\section{REFERÊNCIAS}

AMIGO MONSTRO. Direção: Joe Johnston e Jeff Liu. In: Steven Universe (1a. temporada). Direção: Rebecca Sugar. Burbank: Cartoon Network, 2014. 11m32s, color. Título original: Monster Buddies.

BARDIN, L. Análise de conteúdo. São Paulo: Edições 70.

BETTELHEIM, B. A psicanálise dos contos de fadas. 16 ed. Rio de Janeiro: Paz e Terra, 2002.

BICCA, A. D. N.; CUNHA, A. P. A.; ROSTAS, M. H. S. G.; JAHNKE, M. L. Identidades nerd/geek na web: um estudo sobre pedagogias culturais e culturas juvenis. Conjectura: Filos. Educ. Caxias do Sul, RS, v. 18, n. 1, p. 87-104, 2013. Disponível em: http://www.ucs.br/etc/revistas/index.php/conjectura/article/view/2040/1203. Acesso em 20 ago. 2020

BRASIL. Ministério da Educação. Secretaria da Educação. Base nacional comum curricular. Brasília, DF, 2019. Disponível em: http://basenacionalcomum.mec.gov.br/images/BNCC_EI_EF_110518_versaofinal_site.pdf. Acesso em 01 nov. 2019.

BRASIL. Ministério da Educação. Secretaria da Educação. Parâmetros curriculares nacionais: ensino médio. Brasília, DF, 2000. Disponível em: https://cptstatic.s3.amazonaws.com/pdf/cpt/pcn/bases-legais.pdf. Acesso em 01 set. 2019.

BRASIL. Ministério da Educação. Secretaria da Educação. Parâmetros curriculares nacionais: introdução aos parâmetros curriculares nacionais. Brasília, DF, 1997. Disponível em: http://portal.mec.gov.br/seb/arquivos/pdf/livro01.pdf. Acesso em 01 set. 2019.

BRASIL. Ministério da Educação. Secretaria da Educação. Parâmetros curriculares nacionais: terceiro e quarto ciclos do ensino fundamental - introdução aos Parâmetros curriculares nacionais. Brasília, DF, 1998 . Disponível em: http://portal.mec.gov.br/seb/arquivos/pdf/introducao.pdf. Acesso em: 01 set. 2019.

FANDOM. Steven Universe Wiki: guia de episódios de Steven Universe. Disponível em: https://stevenuniverse.fandom.com/pt-

br/wiki/Guia_de_Epis\%C3\%B3dios_de_Steven_Universe\#1.C2.AA_Temporada:_2014-. Acesso em 5 jun. 2019.

FREIRE, P. Conscientização: teoria e prática da libertação uma introdução ao pensamento de Paulo Freire. São Paulo: Moraes, 1980.

GUSHIKEN, Y.; HIRATA, T. Processos de consumo cultural e midiático: imagem dos 'Otakus', do Japão ao mundo. Intercon - RBCC. n. 37, n. 2, p. 133-152, 2014. Disponível em: http://www.scielo.br/pdf/interc/v37n2/1809-5844-interc-37-02-0133.pdf . Acesso em 20 ago. 2020. 
LACAN, J.: Outros escritos. Rio de Janeiro: Jorge Zahar, 2003.

MINISTÉRIO DA EDUCAÇÃO: Publicações. Disponível em <http://portal.mec.gov.br/conaes-comissaonacional-de-avaliacao-da-educacao-superior/195-secretarias-112877938/seb-educacao-basica-

2007048997/12598-publicacoes-sp-265002211.> Acesso em 20 ago. 2020. 2018.

MIRANDA, O. Tio Patinhas e os mitos da comunicação. São Paulo: Summus, 1978.

MORIN, E. Os sete saberes necessários à educação do futuro. São Paulo: UNESCO/Cortez, 2000.

SÁ-SILVA, J. R.; ALMEIDA, C. D.; GUINDANI; J. F. Pesquisa documental: pistas teóricas e metodológicas. Revista Brasileira de História \& Ciências Sociais. v. 1, n. 1, p. 1-15, 2009. Disponível em: https://www.rbhcs.com/rbhcs/article/viewFile/6/pdf. Acesso em 15 jan. 2019.

SUGAR, R. Guide to the Crystal Gems. New York: Cartoon network Books/Penguin Young Readers Group-Penguin Random House LLC, 2015.

VYGOTSKY, Lev Semenovich. A construção do pensamento e da linguagem. Tradução Paulo Bezerra. São Paulo: Martins Fontes, 2001.

WIKIPEDIA, A enciclopédia livre. Steven Universe. Disponível em: https://pt.wikipedia.org/wiki/Steven_Universe. Acesso em 15 jun. 2019.

Recebido em: 31 de agosto de 2020. Aprovado em: 10 de outubro de 2020. 